\title{
Post-traumatic stress disorder risk and witnessing team members in acute psychological stress during combat
}

\author{
Amy B. Adler, Vlad Svetlitzky and Ian A. Gutierrez
}

\section{Background}

Occupational groups operating in dangerous environments may witness the development of acute stress reaction (ASR) in team members. Witnessing ASR in team members may increase the risk of developing subsequent post-traumatic stress disorder (PTSD) symptoms.

\section{Aims}

To describe ASR symptoms that individuals witness, assess the relationship between witnessing a team member exhibiting ASR symptoms and an individual's own PTSD symptoms, and describe common intervention responses by peers.

\section{Method}

Cross-sectional, anonymous surveys were conducted with US soldiers who were previously deployed (sample $1 ; n=176$ ) and currently deployed sample $2 ; n=497$ ). Surveys assessed combat experiences, PTSD (PTSD Checklist-5), ASR exposure and intervention responses. Analyses included frequencies and binary logistic regression.

\section{Results}

Witnessing at least one ASR symptom during a combat-related event was reported by $51.7 \%$ in sample 1 and $42.4 \%$ in sample 2 the most commonly observed symptoms were being unable to function or being detached. Controlling for combat experiences, high levels of witnessing a team member exhibit ASR symptoms was associated with increased risk of subthreshold PTSD or PTSD in sample 1 (odds ratio $(\mathrm{OR})=8.69,95 \% \mathrm{Cl} 2.29-42.60)$ and approached significance in sample $2(\mathrm{OR}=1.67,95 \% \mathrm{Cl}$ $0.98-2.81$ ). Common intervention responses included providing a directive or yelling; many also reported being unsure how to respond.

\section{Conclusions}

Witnessing team members who exhibit ASR symptoms appears to be associated with screening positive for subthreshold PTSD or PTSD. Results suggest the need for further research into how to prepare individuals to manage ASR in team members and to examine ASR in other high-risk occupations.

\section{Keywords}

Military psychiatry; post-traumatic stress disorder; trauma; social functioning; acute stress.

\section{Copyright and usage}

(C) The Author(S), 2020. Published by Cambridge University Press on behalf of the Royal College of Psychiatrists. This is an Open Access article, distributed under the terms of the Creative Commons Attribution-NonCommercial-ShareAlike licence (http://creativecommons.org/licenses/by-nc-sa/4.0/), which permits non-commercial reuse, distribution, and reproduction in any medium, provided the same Creative Commons licence is included and the original work is properly cited. The written permission of Cambridge University Press must be obtained for commercial re-use.

\section{Acute stress reactions}

Acute stress reactions (ASRs) are a type of momentary, immediate and shifting response to trauma exposure, commonly characterised by a constriction of consciousness, disorientation and physiological symptoms of panic. ${ }^{1}$ Typically, studies on post-traumatic distress are focused on clusters of symptoms that begin several days or weeks following the traumatic event, as exemplified by studies assessing acute stress disorder and post-traumatic stress disorder. ${ }^{2}$ In addition, such studies are focused on the symptomatic individual, ${ }^{3-5}$ not those around the individual who witness that distress.

\section{Acute stress reactions in high-risk occupations}

However, it is important to consider how individual witnesses are affected by being exposed to those exhibiting signs of an ASR in the midst of a traumatic event. Perhaps nowhere is this more relevant than in the military, where teams are expected to function under extremely stressful conditions. In this context, team members depend on one another for survival, so witnessing an individual's failure to function because of an ASR may be particularly stressful because the safety of the entire team may be placed at risk. Furthermore, witnessing close teammates exhibit debilitating anxiety and incapacitating panic may trigger a physiologically and psychologically empathic response, ${ }^{6,7}$ which can elevate the stress levels of team members even further. To date, there are no studies that examine how often service members witness symptoms of
ASR in others. The first goal of the present study was to determine the extent to which service members report witnessing ASR symptoms in team members during combat.

The second goal of the present study was to determine whether witnessing ASR symptoms in team members might function as a specific traumatic stressor associated with the development of post-traumatic stress disorder (PTSD) symptoms. In the military, combatrelated traumatic stressors are strong predictors of subsequent mental health problems in general, ${ }^{8}$ and PTSD in particular ${ }^{9}$ whether measured in terms of diagnostic risk or subthreshold PTSD. ${ }^{10}$ By determining the degree to which witnessing a team member exhibiting ASR symptoms contributes to PTSD symptoms above and beyond other forms of combat exposure, a new risk factor can be identified and potentially addressed clinically and in terms of prevention.

\section{The present study}

In the present study, two different US Army samples were surveyed about their experiences with observing ASR symptoms in team members during combat. Given that ASR symptoms can be exhibited in various ways, soldiers were asked the degree to which they had observed a range of possible ASR symptoms in team members. These two samples were selected in order to assess the relationship between witnessing ASR symptoms in others and PTSD symptoms for samples in both a non-deployed and deployed environment. 
In addition to understanding the frequency of witnessing ASR symptoms in team members and the link to PTSD, it is unclear whether or how those who do witness such reactions intervene. In a high-risk occupation like the military, individuals are trained in combat casualty care and are expected to provide immediate first aid for team members who are physically injured, ${ }^{11}$ yet individuals are not formally trained in how to respond to ASRs that they witness. ${ }^{12}$ In an exploratory analysis, the present study documented the way in which soldiers spontaneously responded to their team members exhibiting ASR symptoms. This descriptive information can be used to identify potential pathways for intervention training.

\section{Method}

\section{Study groups}

Data were collected from two different combat units in 2018 and 2019. For sample 1, 507 soldiers were surveyed at training sites several weeks prior to deploying to Afghanistan. For sample 2, 799 soldiers were surveyed in Afghanistan about half-way through their year-long deployment. In both samples, soldiers who did not participate in the surveys were unavailable largely because of competing duties. Similar surveys have reported participation rates of $62 \%{ }^{13}$ In the present studies, consent rates were $92.2 \%$ for sample 1, and $83.4 \%$ for sample 2 .

The authors assert that all procedures contributing to this work comply with the ethical standards of the relevant national and institutional committees on human experimentation and with the Helsinki Declaration of 1975, as revised in 2008. All procedures involving human participants were approved by the Human Subjects Protection Branch of the Walter Reed Army Institute of Research and a non-research determination was issued (Protocol \#2692). Written informed consent was obtained from all participants. All surveys were administered in small groups in unit classrooms or tents.

Given the study's focus on ASR in the context of combat-related events, data-sets for analysis excluded soldiers who did not report at least one combat-related event and who had not completed at least one combat deployment lasting at least 30 days. Consequently, 176 soldiers from sample 1 (or $34.7 \%$ ) and 497 soldiers from sample 2 (or $62.2 \%$ ) were selected for analysis. The groups are thus labelled previously deployed and currently deployed.

PTSD symptoms were assessed with the 20-item PTSD Checklist (PCL-5). ${ }^{14}$ Items paralleled PTSD symptom clusters and diagnostic criteria in the DSM-5, ${ }^{15}$ with symptom severity rated on a 5 -point scale ( 0 , not at all; 4 , extremely). Participants were regarded as screening positive for PTSD if they endorsed at least one intrusion symptom, one avoidance symptom, two negative alterations in cognition or mood symptoms, and two hyperarousal symptoms at the moderate level or above. Based on recommendations from McLaughlin et al, ${ }^{16}$ subthreshold PTSD was operationalised as screening positive on two symptom clusters or more. Internal consistency was satisfactory in sample $1(\alpha=0.94)$, and sample $2(\alpha=0.95)$.

Combat experiences were measured with items adapted from the combat experiences scale used in previous military research., ${ }^{9,17}$ The measure comprised eight items (for example knowing someone seriously injured or killed; being wounded/injured; had a buddy shot or hit who was near you), rated for frequency $(0$, never; 1,1 time; 2, 2-4 times; to 3, 5 or more times). Items were dichotomised (never vs. at least once), then summed, consistent with previous research, ${ }^{18,19}$ and divided into low (1-2), medium (3-4) or high (5 or higher) levels of experience.

Witnessing acute stress symptoms in team members was assessed using items developed for this study. Participants were provided a prompt, 'During a significant combat-related event (such as a firefight or IED [improved explosive device]), I encountered a service member who was so mentally stressed that...', and then asked to rate six items (for example they were unable to function for a period of time during the event) on a four-point scale ( 0 , did not experience; 1 , experienced one time; 2 , experienced two times; or 3, experienced three times or more). Consistent with the combat experiences scale, items were dichotomised (never vs. at least once) and then summed. The sum, ranging from 0 to 6 , reflected the amount of witnessing ASR symptoms. Three categories were created ( 0 , no witnessing an ASR; 1 to 3, low level of witnessing an ASR; 4 to 6 experiences, high level of witnessing). The dichotomised items demonstrated satisfactory internal consistency in sample $1(\alpha=0.85)$ and sample $2(\alpha=0.92)$.

Intervention response to witnessing an ASR was assessed with eight items (for example does not apply - I did not encounter this situation; was uncertain how to respond; shook them/hit them/ pushed them; directed them to perform a simple task). These items, developed for the present study, were generated based on expert feedback from a peer-based initiative to manage ASRs in team members and compiled by the authors, who had experience in deployment mental health. ${ }^{20}$ Respondents were instructed to mark all of the items that applied; multiple items could be endorsed. Items assessing intervention response types are not expected to be internally consistent, as these items reflect potential responses to witnessing an ASR. Nevertheless, the dichotomised items demonstrated acceptable internal consistency in sample $1(\alpha=0.65)$ and sample $2(\alpha=0.73)$.

\section{Data analyses}

PTSD prevalence and subthreshold PTSD, exposure to ASR in team members, and responses were calculated for both samples. Given overall PTSD screening prevalence was low in both samples, we combined those who screened positive at the subthreshold PTSD level or at the PTSD level (subthreshold PTSD or PTSD). This combined PTSD measure was regressed on ASR exposure sum controlling for combat experiences using binary logistic regression. Adjusted odds ratios (AOR), with 95\% confidence intervals, were calculated. All analyses were two-tailed. Statistical analysis was conducted using SPSS version 24.0 and the R statistical package version 3.6.1.

\section{Results}

The demographic characteristics of participants from the two samples are presented in Table 1. Both samples were predominantly men, married and non-commissioned officers. In terms of age, the majority of sample 1 was 30-39 years old, and the modal age for sample 2 was $30-39$ years old. Chi-square analysis demonstrate that soldiers in sample 1 were, on average, older, higher ranking and less likely to be active duty than soldiers in sample 2. Across both samples, more than 5\% screened positive for PTSD, and $13.1 \%$ and $25.1 \%$ screened positive for subthreshold PTSD or PTSD in samples 1 and 2, respectively.

Among soldiers who reported that they had witnessed team members exhibit ASR symptoms, at least one encounter was reported by $51.7 \%$ of sample 1 , and $42.4 \%$ of sample 2 . Data on specific soldier experiences with witnessing ASR symptoms in team members are presented in Table 2. These data suggest that witnessing team members experience an ASR in a combat environment is relatively common. Although ASR symptoms can take different forms, the symptoms most frequently observed appear to be those related to being unable to function, reported by more than $39 \%$, and being detached, reported by more than $33 \%$. Similarly, more than $31 \%$ reported witnessing team members who potentially 


\begin{tabular}{|c|c|c|c|c|c|c|}
\hline \multirow[b]{3}{*}{ Characteristic } & \multicolumn{2}{|c|}{ Army study groups } & & & & \\
\hline & \multirow{2}{*}{$\begin{array}{l}\text { Sample 1: previously deployed }(n=176) \\
n(\%)\end{array}$} & \multirow{2}{*}{$\begin{array}{l}\text { Sample 2: currently deployed }(n=497) \\
n(\%)\end{array}$} & \multicolumn{4}{|c|}{$\chi^{2}$ test of independence } \\
\hline & & & $\chi^{2}$ & d.f. & Residual $^{\mathrm{b}}$ & $P$ \\
\hline \multicolumn{3}{|l|}{ Age, years } & 30.10 & 3 & & $<0.001$ \\
\hline $18-24$ & $1(0.6)$ & $63(12.8)$ & & & -4.69 & $<0.001$ \\
\hline $25-29$ & $28(16.1)$ & $114(23.1)$ & & & -1.04 & 0.422 \\
\hline $30-39$ & $120(69.0)$ & $255(51.6)$ & & & 3.97 & 0.001 \\
\hline$\geq 40$ & $25(14.4)$ & $62(12.6)$ & & & 0.61 & 1.000 \\
\hline \multicolumn{3}{|l|}{ Gender } & $<0.01$ & 1 & & 1.000 \\
\hline Men & $169(96.0)$ & $476(96.0)$ & & & 0.03 & 1.000 \\
\hline Women & $7(4.0)$ & $20(4.0)$ & & & -0.03 & 1.000 \\
\hline \multicolumn{3}{|l|}{ Marital status } & 3.58 & 3 & & 0.310 \\
\hline Single, never married & 25 (14.3) & $70(14.3)$ & & & 0.01 & 1.000 \\
\hline Married & $123(70.3)$ & $364(74.1)$ & & & -0.99 & 1.000 \\
\hline Separated & $3(1.7)$ & $13(2.6)$ & & & -0.62 & 1.000 \\
\hline Divorced & $24(13.7)$ & $44(9.0)$ & & & 1.78 & 0.597 \\
\hline \multicolumn{3}{|l|}{ Grade/rank } & 11.83 & 2 & & 0.003 \\
\hline Junior enlisted (E1-E4) & $4(2.3)$ & $52(10.5)$ & & & -3.36 & 0.005 \\
\hline Non-commissioned officer (E5-E9) & $128(73.6)$ & $321(64.8)$ & & & 2.10 & 0.212 \\
\hline Officer/warrant officer & $42(24.1)$ & $122(24.6)$ & & & -0.13 & 1.000 \\
\hline \multicolumn{7}{|l|}{ Component } \\
\hline Active duty & $117(66.5 \%)$ & $497(100)$ & 178.45 & 1 & & $<0.001$ \\
\hline Reserve/National Guard & 59 (33.5\%) & $0(0)$ & & & - & - \\
\hline \multicolumn{3}{|l|}{ Combat experiences } & 6.50 & 2 & & 0.039 \\
\hline $1-2$ & $53(30.1)$ & $202(40.6)$ & & & -2.49 & 0.080 \\
\hline $3-4$ & $56(31.8)$ & $125(25.2)$ & & & 1.71 & 0.519 \\
\hline 5 or more & $67(38.1)$ & $170(34.2)$ & & & 0.92 & 1.000 \\
\hline \multicolumn{3}{|l|}{ Witnessing an ASR } & 11.62 & 2 & & 0.003 \\
\hline No witnessing an ASR & $77(44.0)$ & $271(55.3)$ & & & -2.57 & 0.061 \\
\hline Low level of witnessing an ASR & $52(29.7)$ & $88(18.0)$ & & & 3.27 & 0.006 \\
\hline High level of witnessing an ASR & $46(26.3)$ & $131(26.7)$ & & & -0.12 & 1.000 \\
\hline \multicolumn{3}{|l|}{ PTSD Symptomatology } & 15.12 & 2 & & 0.001 \\
\hline PTSD (PCL-5) & $11(6.3)$ & $29(5.8)$ & & & 0.20 & 1.000 \\
\hline Subthreshold PTSD (PCL-5) & $12(6.8)$ & $96(19.3)$ & & & -3.88 & 0.001 \\
\hline No PTSD & $153(86.9)$ & $372(74.8)$ & & & 3.33 & 0.005 \\
\hline \multicolumn{7}{|c|}{$\begin{array}{l}\text { PTSD, post-traumatic stress disorder; PCL-5, PTSD Checklist-5; ASR, acute stress disorder. } \\
\text { a. Data show the valid per cent without missing values. Percentages may add to more than } 100 \text { because of rounding. } \\
\text { b. Residuals for post hoc chi-square analysis are presented in standardised adjusted format. Positive residuals reflect higher observed cell counts in sample } 1 \text { as compared with sample } \\
\text { 2. Significant tests for chi-square family-wise residuals corrected with Bonferroni adjustment. For values with no observations, residuals could not be calculated. }\end{array}$} \\
\hline
\end{tabular}

increased risk to the individual and team, and more than $31 \%$ reported witnessing team members who were emotionally overwhelmed. In contrast, witnessing team members who were confused was comparatively less common, although still reported by more than $25 \%$ of respondents, as was witnessing team members who were erratic and agitated, reported by more than $19 \%$ of respondents.

At the bivariate level, witnessing one or more ASRs in team members was positively and significantly associated with meeting full diagnostic criteria for PTSD in sample $1(r=0.18, P=0.016)$ and sample $2(r=0.11, P=0.018)$. Witnessing one or more ASRs in team members was also positively and significantly associated with meeting diagnostic criteria for PTSD or subthreshold PTSD in sample $1(r=0.24, P=0.001)$ and sample $2(r=0.17, P<0.001)$. We examined these relationships in greater depth with binary logistic regression models. These models demonstrated that after adjusting for combat experiences, high levels of witnessing a team member exhibiting ASR symptoms remained significantly associated with the combined subthreshold PTSD/PTSD category in sample 1 and approached significance in sample 2. Full model details are reported in Table 3.

Frequencies regarding how soldiers intervened in response to ASRs that they witnessed are listed in Table 4 . In sample 1, the most common responses reported were providing a directive, yelling and trying to calm the team member down. In sample 2, the most common responses were trying to calm the team member down, getting someone else to help and assertively getting their attention. Although relatively less common, 7\% of sample 1 and $16 \%$ of sample 2 reported being uncertain how to respond, and $17 \%$ of sample 1 and $8 \%$ of sample 2 reported shaking, hitting or pushing the team member.

\section{Discussion}

\section{Main findings}

Findings from two different samples of US soldiers demonstrated that witnessing ASR symptoms in team members is relatively common. In a sample of soldiers surveyed before deployment (sample 1), $51.7 \%$ of those who had previous deployment experience reported witnessing an ASR, and in another sample (sample 2), $42.4 \%$ of soldiers surveyed during deployment reported witnessing an ASR. To our knowledge, this is the first study to show the proportion of soldiers witnessing ASR symptoms in team members. Overall, $13.1 \%$ of soldiers surveyed at pre-deployment and $25.1 \%$ of soldiers surveyed during deployment screened positive for subthreshold PTSD or PTSD. In the participants assessed prior to deployment, the odds of screening positive were significantly greater in soldiers reporting high levels of witnessing an ASR, and in the sample assessed during deployment, these odds were marginally significant. However, in both samples, the pattern of results showed a link between witnessing an ASR and screening positive for subthreshold PTSD or PTSD. 


\begin{tabular}{|c|c|c|c|c|}
\hline \multirow[b]{3}{*}{ ASR symptoms encountered ${ }^{\mathrm{b}}$} & \multicolumn{4}{|c|}{ Study group } \\
\hline & \multicolumn{2}{|c|}{$\begin{array}{l}\text { Sample 1: previously deployed } \\
\qquad(n=176)\end{array}$} & \multicolumn{2}{|c|}{$\begin{array}{l}\text { Sample 2: currently deployed } \\
\qquad(n=497)\end{array}$} \\
\hline & $n$ & $\%$ & $n$ & $\%$ \\
\hline Unable to function ${ }^{c}$ & \multicolumn{2}{|l|}{176} & \multicolumn{2}{|l|}{492} \\
\hline 0 & 106 & 60.2 & 299 & 60.8 \\
\hline 1 & 39 & 22.2 & 83 & 16.9 \\
\hline 2 & 18 & 10.2 & 54 & 11.0 \\
\hline 3 or more & 13 & 7.4 & 56 & 11.4 \\
\hline Increased risk ${ }^{d}$ & \multicolumn{2}{|l|}{176} & \multicolumn{2}{|l|}{493} \\
\hline 0 & 117 & 66.5 & 338 & 68.6 \\
\hline 1 & 32 & 18.2 & 72 & 14.6 \\
\hline 2 & 19 & 10.8 & 45 & 9.1 \\
\hline 3 or more & 8 & 4.5 & 38 & 7.7 \\
\hline Detached $^{\mathrm{e}}$ & \multicolumn{2}{|l|}{176} & \multicolumn{2}{|l|}{493} \\
\hline 0 & 106 & 60.2 & 328 & 66.5 \\
\hline 1 & 41 & 23.3 & 84 & 17.0 \\
\hline 2 & 19 & 10.8 & 44 & 8.9 \\
\hline 3 or more & 10 & 5.7 & 37 & 7.5 \\
\hline Erratic and agitated $^{f}$ & \multicolumn{2}{|l|}{176} & \multicolumn{2}{|l|}{493} \\
\hline 0 & 138 & 78.4 & 398 & 80.7 \\
\hline 1 & 18 & 10.2 & 43 & 8.7 \\
\hline 2 & 12 & 6.8 & 21 & 4.3 \\
\hline 3 or more & 8 & 4.5 & 31 & 6.3 \\
\hline \multicolumn{3}{|l|}{ Emotionally overwhelmed ${ }^{g}$} & \multicolumn{2}{|l|}{493} \\
\hline 0 & 121 & 68.8 & 337 & 68.4 \\
\hline 1 & 30 & 17.0 & 79 & 16.0 \\
\hline 2 & 14 & 8.0 & 42 & 8.5 \\
\hline 3 or more & 11 & 6.3 & 35 & 7.1 \\
\hline \multicolumn{3}{|l|}{ Extremely confused ${ }^{\text {h }}$} & \multicolumn{2}{|l|}{492} \\
\hline 0 & 129 & 73.7 & 369 & 75.0 \\
\hline 1 & 32 & 18.3 & 67 & 13.6 \\
\hline 2 & 8 & 4.6 & 28 & 5.7 \\
\hline 3 or more & 6 & 3.4 & 28 & 5.7 \\
\hline \multicolumn{5}{|c|}{$\begin{array}{l}\text { a. Response options were coded as } 0 \text {, did not experience; } 1 \text {, experienced one time; } 2 \text {, experienced two times; } 3 \text { experienced three times or more. } \\
\text { b. Items were list after the following prompt: 'During a significant combat-related event I encountered a service member who was so mentally stressed that....' } \\
\text { c. They were unable to function for a period of time during the event. } \\
\text { d. Their difficulty in functioning increased risk to themselves and/or fellow service members. } \\
\text { e. They were detached from what was happening (such as being 'frozen', not responding, having a thousand-yard stare). } \\
\text { f. They were erratic and agitated (such as dropping gear/weapon, running without regard to danger, or firing without purpose). } \\
\text { g. They were emotionally overwhelmed (such as yelling, crying or gasping). } \\
\text { h. They were extremely confused (such as repeating phrases, speaking in fragments or speaking without regard to sequence of events). }\end{array}$} \\
\hline
\end{tabular}

\section{Interpretation of our results}

Although the mechanism driving the link between witnessing ASR symptoms in team members and screening positive for subthreshold PTSD or PTSD is not explicitly studied here, the relationship may be driven by a sense of threat. In terms of direct threat, witnessing a team member be unable to engage in mission-related tasks may exacerbate an individual's sense of danger because the team's mission effectiveness is jeopardised. In terms of indirect threat, individuals may respond to observing acute stress in others with physiological and psychological empathy that heightens their own distress. ${ }^{21}$ It would be important to understand the neural mechanisms that explains these relationships and to consider the potential role of mirror neurons. ${ }^{22}$

Witnessing an ASR was positively associated with screening positive for subthreshold PTSD or PTSD at the bivariate level in both samples. However, closer analysis with binary logistic regression in the two study samples yielded slightly different results in terms of the association of witnessing ASR symptoms and screening positive for subthreshold PTSD or PTSD. The observation that more soldiers who had previously deployed reported witnessing ASR symptoms in team members than those currently deployed makes sense given that they also reported more previous combat experiences than those currently deployed, and thus, had more exposure to events that may have elicited ASRs in team members. Consistent with this greater level of deployment experience, we also note that sample 1 had older and more senior-ranking soldiers compared with sample 2 .

Differences between the samples in screening positive for subthreshold PTSD and PTSD may also reflect the impact of the deployment cycle on symptom presentation. It could be, for example, that anticipatory anxiety and cognitive depletion associated with an upcoming combat deployment ${ }^{23}$ made concerns salient for sample 1 about the degree to which team members would be unable to function under the strain of combat, and thus strengthened the link between memories of witnessing a team mate experience an ASR and their own PTSD symptoms. Alternatively, it could be that during deployment, the experience of witnessing ASRs in team members is less related to screening positive for subthreshold PTSD or PTSD than during the predeployment phase. It may be that soldiers during deployment are confronted with myriad other stressors and hassles that influence PTSD-related symptoms. ${ }^{24,25}$

\section{Dose-response relationship}

Despite differences in levels of significance regarding these relationships, both samples demonstrated evidence of a dose-response relationship between the extent to which an individual reported witnessing a team member exhibit ASR symptoms and the individual's likelihood of screening positive for subthreshold PTSD or 


\begin{tabular}{|c|c|c|c|c|}
\hline Variable & $B$ & s.e. & Odds ratio & $95 \% \mathrm{Cl}$ \\
\hline \multicolumn{5}{|l|}{ Sample 1: Previously deployed $(n=175)$} \\
\hline \multicolumn{5}{|c|}{ Combat experiences } \\
\hline $1-2^{b}$ & - & - & - & - \\
\hline $3-4$ & 1.09 & 0.85 & 2.98 & $0.64-21.40$ \\
\hline 5 or more & 0.73 & 0.87 & 2.07 & $0.44-15.26$ \\
\hline \multicolumn{5}{|l|}{ Witnessing an ASR } \\
\hline No witnessing an $\mathrm{ASR}^{\mathrm{C}}$ & - & - & - & - \\
\hline Low levels of witnessing an ASR & 0.95 & 0.77 & 2.58 & $0.59-13.60$ \\
\hline \multirow{2}{*}{\multicolumn{5}{|c|}{ Model fit }} \\
\hline & & & & \\
\hline Model $\chi^{2}$ & $10.02^{\star \star}$ & & & \\
\hline Model d.f. & 4 & & & \\
\hline Nagelkerke $R^{2}$ & 0.193 & & & \\
\hline \multicolumn{5}{|l|}{ Sample 2: currently deployed $(n=490)$} \\
\hline \multicolumn{5}{|l|}{ Combat experiences } \\
\hline $1-2^{b}$ & _- & _- & _ & _- \\
\hline 3-4 & 0.48 & 0.30 & 1.61 & $0.90-2.90$ \\
\hline 5 or more & $0.93^{\star \star}$ & 0.28 & 2.53 & $1.46-4.43$ \\
\hline \multicolumn{5}{|l|}{ Witnessing an ASR } \\
\hline No witnessing an $\mathrm{ASR}^{\mathrm{C}}$ & - & - & - & - \\
\hline Low levels of witnessing an ASR & 0.37 & 0.29 & 1.45 & $0.80-2.56$ \\
\hline High levels of witnessing an ASR & 0.51 & 0.27 & 1.67 & $0.98-2.81$ \\
\hline \multicolumn{5}{|l|}{ Model fit } \\
\hline Model $\chi^{2}$ & $25.90^{\star \star *}$ & & & \\
\hline Model d.f. & 4 & & & \\
\hline Nagelkerke $R^{2}$ & 0.105 & & & \\
\hline \multicolumn{5}{|c|}{$\begin{array}{l}\text { PCL-5, PTSD Checklist; ASR, acute stress reaction. } \\
\text { a. Subthreshold PTSD or PTSD included both those scoring above subthreshold and those scoring above threshold for PTSD. The model for sample } 1 \text { removed } 1 \text { missing cases }(0.5 \%) \text {. The } \\
\text { model for sample } 2 \text { removed } 7 \text { missing cases (1.4\%). } \\
\text { b. Combat experience was calculated in terms of frequency of exposure to eight combat experiences in which items were dichotomised and then summed. } \\
\text { c. Witnessing an ASR was calculated in terms of severity of exposure to a team member exhibiting ASR symptoms in which six items were dichotomised and then summed, with low levels } 1- \\
3 \text { and high levels } 4-6 \text {. } \\
* * P<0.01 ; * \star * P<0.001 \text {. }\end{array}$} \\
\hline
\end{tabular}

PTSD. That is, greater ASR exposure was positively associated with a greater likelihood of PTSD-related symptomatology both at the bivariate and multivariate level. Thus, it is important for future research to examine these relationships in other samples and to better understand the degree to which witnessing ASR symptoms in others may influence screening positive for subthreshold PTSD or PTSD at different phases of the deployment cycle.

\section{Comparison with findings from other studies}

In both samples, the proportion screening positive for subthreshold PTSD or PTSD is generally consistent with the range of 6.9 to $22.3 \%$ obtained from a range of self-report criteria across 16 studies ${ }^{26}$ and $13.5 \%$ reporting past-month prevalence in a national sample of veterans with and without combat deployment experience. ${ }^{27}$ Subthreshold PTSD symptoms have also been identified as associated with comorbidity and decrements in functioning. ${ }^{27}$

\section{Implications}

Given that witnessing ASR symptoms in team members appears associated with screening positive for subthreshold PTSD or PTSD, it may be useful for researchers to broaden combat experience scales to include this kind of exposure. In addition, results highlighted a diversity of intervention responses from individuals who witnessed team members exhibiting ASR symptoms. These findings suggest that there is diversity in intervention responses and a potential training opportunity to help individuals learn how

\section{Table 4 Soldier intervention in response to witnessing a team member exhibit acute stress reaction (ASR) symptoms ${ }^{a}$}

\begin{tabular}{|c|c|c|c|c|}
\hline \multirow[b]{3}{*}{ Responses } & \multicolumn{4}{|c|}{ Study group subsamples } \\
\hline & \multicolumn{2}{|c|}{$\begin{array}{l}\text { Sample 1: previously } \\
\text { deployed }(n=96)\end{array}$} & \multicolumn{2}{|c|}{$\begin{array}{l}\text { Sample 2: currently deployec } \\
(n=207)\end{array}$} \\
\hline & $n$ & $\%$ & $n$ & $\%$ \\
\hline Was uncertain how to respond & 7 & 7.3 & 34 & 16.4 \\
\hline Tried to calm them down by speaking quietly to them & 24 & 25.0 & 104 & 50.2 \\
\hline Yelled at them to get them to snap out of it & 32 & 33.3 & 47 & 22.7 \\
\hline Shook them/hit them/pushed them & 15 & 15.6 & 17 & 8.2 \\
\hline Directed them to perform a simple task & 35 & 36.5 & 65 & 31.4 \\
\hline Told them what was happening & 18 & 18.8 & 50 & 24.2 \\
\hline Assertively got their attention & 20 & 20.8 & 66 & 31.9 \\
\hline Got someone else to help & 12 & 12.5 & 77 & 37.2 \\
\hline
\end{tabular}


to best respond. Not only would such training enable them to potentially address ASR in others and return an affected team member to functioning, but it may enable them to feel more efficacious when confronted with an acutely stressed team member.

Recently, training for rapid peer-based management of ASRs in team members has been developed and integrated into the Israel Defense Forces. ${ }^{2,21}$ Results from cross-sectional data suggest that for soldiers witnessing ASRs symptoms in team members, this training is associated with better outcomes. ${ }^{20}$ This training, designed for non-medical unit members, has since been adapted for service members in the USA, and data demonstrate perceived utility and feasibility. ${ }^{12}$ Future research should continue to examine the impact of such peer-based training on individual witnesses in terms of their actual behavior and their long-term mental health and examine the impact on their affected team members over time.

\section{Limitations}

There are several study limitations to consider. First, the study is limited by the fact that individuals may have been distracted during the combat-related event and possibly by their own cooccurring ASR. This limitation may have led individuals to underreport the symptoms of others, and an individual's own ASR should also be modelled in these relationships. Second, data are correlational, thus causality cannot be established in terms of witnessing ASR symptoms and subsequent PTSD symptoms.

Third, measures did not permit analysis of how much time had elapsed since the event occurred so the impact over time could not be assessed. Fourth, there was low incidence of screening positive for subthreshold PTSD or PTSD in sample 1, leading to less precise estimates of effect. Fifth, the small sample for sample 1 resulted in small numbers within each category, leading to large confidence intervals and implying results should be interpreted cautiously.

Sixth, although the measures of ASR symptoms and intervention behaviours demonstrated satisfactory internal consistency, they have not been validated. Finally, it is important to note that the estimates reported here do not represent how common an ASR may be in such high-risk situations like combat but rather how often individuals witness team members exhibiting ASR symptoms.

\section{Future directions}

Although gaps remain in the literature, the present study suggests avenues for future research. For example, future research should examine the impact of witnessing a team member exhibit ASR symptoms on a range of mental health-related outcomes, including secondary traumatisation. ${ }^{21,28}$ Follow-on studies should also examine the factors that influence the decision to intervene and the way in which individuals intervene. Research in civilian and military contexts has demonstrated the importance of understanding the dynamics of bystander intervention and what factors may inhibit intervention. ${ }^{29-31}$

Future work should also validate the measure of witnessing ASR symptoms by, for example, conducting semi-structured interviews, examining group-level properties of data reported by teams exposed to traumatic stressors, and obtaining responses to individuals observing depictions of an ASR. Likewise, validation of the measure of intervention responses should also be pursued through semi-structured interviews of team members and those who report having experienced ASR symptoms, and through systematic observation during planned military exercises. The fact that there was acceptable consistency across items in the scale suggest that some of these behaviours may co-occur, and future research can consider how these behaviours cluster together. Finally, future work should continue to examine these relationships over time and encompass not only military samples but also other high-risk occupations.

Amy B. Adler (D), PhD, Research Transition Office, Walter Reed Army Institute of Research, USA; Vlad Svetlitzky (D), PhD, Research Transition Office, Walter Reed Army Institute of Research, USA; Ian A. Gutierrez, PhD, Research Transition Office, Walter Reed Army Institute of Research, USA

Correspondence: Amy B. Adler. Email: amy.b.adler.civ@mail.mil

First received 30 Jan 2020, final revision 3 Jul 2020, accepted 27 Jul 2020

\section{Data availability}

The data that support the findings of this study are available on request from the corresponding author, A.B.A. The data are not publicly available due to restrictions related to human participants protection requirements within the Institute.

\section{Acknowledgements}

We thank Lyndon Riviere (protocol principal investigator for sample 1), Paul Kim (senior research associate), and Julie Merrill (senior research associate) for their support of this project. Material has been reviewed by the Walter Reed Army Institute of Research. There is no objection to its presentation and/or publication. The opinions or assertions contained herein are the private views of the author, and are not to be construed as official, or as reflecting true views of the Department of the Army or the Department of Defense. The investigators have adhered to the policies for protection of human subjects as prescribed in AR 70-25.

\section{Author contributions}

A.B.A. formulated the research questions, designed the study and served as lead author. V.S formulated the research questions, analysed the data, and co-wrote the article. I.A.G. assisted with statistical consultation, data analysis and manuscript revision.

\section{Funding}

This research was supported by core funding from the Military Operational Medicine Research Program, the US Army Medical Research and Development Command.

\section{Declaration of interest}

None.

ICMJE forms are in the supplementary material, available online at https://doi.org/10.1192/ bjo.2020.81.

\section{References}

1 World Health Organization. Classifications of Mental and Behavioural Disorder: Clinical Descriptions and Diagnostic Guidelines (ICD-11). World Health Organization, 2018 (https://icd.who.int/browse11/l-m/en).

2 Svetlitzky V, Farchi M, Ben Yehuda A, Adler AB. YaHaLOM: a rapid intervention for acute stress reactions in high-risk occupations. Mil Behav Health 2020; 8: 232-42.

3 Adler AB, Wright KM, Bliese PD, Eckford R, Hoge CW. A2 diagnostic criterion for combat-related posttraumatic stress disorder. J Trauma Stress 2008; 21: 301-8.

4 Thomas É, Saumier D, Brunet A. Peritraumatic distress and the course of posttraumatic stress disorder symptoms: a meta-analysis. Can J Psychiatry 2012; 57: 122-9.

5 Vance MC, Kovachy B, Dong M, Bui E. Peritraumatic distress: a review and synthesis of 15 years of research. J Clin Psychol 2018; 74: 1457-84.

6 Feigin S, Owens G, Goodyear-Smith F. Theories of human altruism: a systematic review. J Psychiatry Brain Funct 2018; 1: 1-8.

7 Liu L, Ito W, Morozov A. GABAb receptor mediates opposing adaptations of GABA release from two types of prefrontal interneurons after observational fear. Neuropsychopharmacology 2017; 42: 1272-83.

8 Stevelink SA, Jones M, Hull L, Pernet D, MacCrimmon S, Goodwin L, et al. Mental health outcomes at the end of the British involvement in the Iraq and Afghanistan conflicts: a cohort study. Br J Psychiatry 2018; 213: 690-7.

9 Hoge CW, Castro CA, Messer SC, McGurk D, Cotting DI, Koffman RL. Combat duty in Iraq and Afghanistan, mental health problems, and barriers to care. $N$ Engl J Med 2004; 351: 13-22.

10 Bergman HE, Przeworski A, Feeny NC. Rates of subthreshold PTSD among U.S. military veterans and service members: a literature review. Mil Psychol 2017; 29: 117-27.

11 Butler F. Tactical combat casualty care: beginnings. Wilderness Environ Med 2017: 28: S12-7. 
12 Adler AB, Start AR, Milham L, Allard YS, Riddle D, Townsend L, et al. Rapid response to acute stress reaction: pilot-test of iCOVER training for military units. Psychol Trauma 2019; 12: 431-5.

13 Thomas JL, Wilk JE, Riviere LA, McGurk D, Castro CA, Hoge CW. Prevalence of mental health problems and functional impairment among active component and National Guard soldiers 3 and 12 months following combat in Iraq. Arch Gen Psychiatry 2010; 67: 614-23.

14 Weathers FW, Litz BT, Keane TM, Palmieri PA, Marx BP, Schnurr PP. The PTSD Checklist for DSM-5 (PCL-5). National Center for PTSD, 2013 (www.ptsd.va.gov).

15 American Psychiatric Association. Diagnostic and Statistical Manual of Mental Disorders (5th edn) DSM-5. APA, 2013.

16 McLaughlin KA, Koenen KC, Friedman MJ, Ruscio AM, Karam EG, Shahly V, et al Subthreshold posttraumatic stress disorder in the world health organization world mental health surveys. Biol Psychiatry 2015; 77: 375-84.

17 Adler AB, Britt TW, Castro CA, McGurk D, Bliese PD. Effect of transition home from combat on risk-taking and health-related behaviors. J Trauma Stress 2011; 24: 381-9.

18 Britt TW, Adler AB, Sawhney G, Bliese PD. Coping strategies as moderators of the association between combat exposure and posttraumatic stress disorder symptoms. J Trauma Stress 2017; 30: 491-501.

19 Sundin J, Herrell RK, Hoge CW, Fear NT, Adler AB, Greenberg N, et al. Mental health outcomes in US and UK military personnel returning from Iraq. $\mathrm{Br} J$ Psychiatry 2014; 204: 200-7.

20 Svetlitzky V, Farchi M, Ben Yehuda A, Start AR, Levi O, Adler AB. YaHaLOM training in the military: assessing knowledge, confidence, and stigma. Psychol SerV 2019; 17: 1519

21 Svetlitzky V, Farchi M, Ben $Y$, Adler AB. Witnessing acute stress reaction in team members: the moderating effect of YaHaLOM. J Nerv Ment Dis [Epub ahead of printl $29 \mathrm{Jul}$ 2020. Available from: http://doi.org/10.1097/NMD. 0000000000001218

22 Iacoboni M. Imitation, empathy, and mirror neurons. Annu Rev Psychol 2009; 60: $653-70$
23 Jha AP, Stanley EA, Kiyonaga A, Wong L, Gelfand L. Examining the protective effects of mindfulness training on working memory capacity and affective experience. Emotion 2010; 10: 54-64.

24 Heron EA, Bryan CJ, Dougherty CA, Chapman WG. Military mental health: the role of daily hassles while deployed. J Nerv Ment Dis 2013; 201: 1035-9.

25 Ramchand R, Rudavsky R, Grant S, Tanielian T, Jaycox L. Prevalence of, risk factors for, and consequences of posttraumatic stress disorder and other mental health problems in military populations deployed to Iraq and Afghanistan. Curr Psychiatry Rep 2015; 17: 37

26 Bergman HE, Przeworski A, Feeny NC. Rates of subthreshold PTSD among US military veterans and service members: a literature review. Mil Psychol 2017; 29: $117-27$.

27 Mota NP, Tsai J, Sareen J, Marx BP, Wisco BE, Harpaz-Rotem I, et al. High burden of subthreshold DSM-5 post-traumatic stress disorder in US military veterans. World Psychiatry 2016; 15: 185-6.

28 Penix EA, Kim PY, Wilk JE, Adler AB. Secondary traumatic stress in deployed healthcare staff. Psychol Trauma 2018; 11: 1-9.

29 Brewster M, Tucker JM. Understanding bystander behavior: the influence of and interaction between bystander characteristics and situational factors. Vict Offenders 2016; 11: 455-81.

30 Burn SM. Appeal to bystander interventions: a normative approach to health and risk messaging. In Oxford Research Encyclopedia of Communication. Oxford University Press, 2017. (https://doi.org/10.1093/ acrefore/9780190228613.013.242)

31 Elliman TD, Shannahoff ME, Metzler JN, Toblin RL. Prevalence of bystander intervention opportunities and behaviors among US Army Soldiers. Health Educ Behav 2018; 45: 741-7 